\title{
PENGARUH KOMPETENSI KERJA, DISIPLIN KERJA DAN KEPUASAN KERJA TERHADAP KINERJA KARYAWAN PT NASATECH SUKSES ABADI
}

\author{
THE EFFECT OF WORK COMPETENCY, WORK DISCIPLINE AND \\ SATISFACTION ON EMPLOYEE PERFORMANCE \\ PT NASATECH SUKSES ABADI
}

\author{
Angles Williams', Purnama Yanti Purba' ${ }^{2}$, Vina Prenita ${ }^{3}$, \\ Melinawaty Lumban Tobing ${ }^{4}$ \\ Universitas Prima Indonesia ${ }^{1,2,3,4}$ \\ angleswilliams948@gmail.com ${ }^{1}$
}

\begin{abstract}
Employees have a big role in fulfilling fluency in the field of organization. Organizations need human resources to develop their businesses. This study aims to examine and analyze the effect of competence, work discipline, and job satisfaction on employee performance at PT Nasatech Sukses Abadi Medan. The phenomenon of performance instability that can be seen from the achievement of the company's targets caused by lack of competence and employee work discipline and a decrease in employee job satisfaction is the background of this study. The research method used is a quantitative approach, the type of research is quantitative descriptive, and the nature of this study is descriptive explanatory. The data analysis method is multiple linear regression analysis. The sampling technique uses the saturation sampling method. The study sample was 83 employees. The results of this study prove the existence of a significant and positive influence on competence, work discipline, and job satisfaction have a positive and significant effect on employee performance at PT Nasatech Sukses Abadi Medan.
\end{abstract}

Keywords: Competence, Work Discipline, Job Satisfaction, Employee Performance

\begin{abstract}
ABSTRAK
Karyawan memiliki peranan besar dalam memenuhi kelancaran di bidang organisasi. Organisasi perlu sumber daya manusia guna mengembangkan usahanya. Penelitian ini bertujuan untuk menguji dan menganalisis pengaruh kompetensi, disiplin kerja, dan kepuasan kerja terhadap kinerja karyawan pada PT Nasatech Sukses Abadi Medan. Fenomena ketidakstabilan kinerja yang terlihat dari tidak tercapainya target perusahaan yang disebabkan oleh kurangnya kompetensi dan disiplin kerja karyawan serta penurunan kepuasan kerja karyawan melatarbelakangi penelitian ini. Metode penelitian yang digunakan adalah pendekatan kuantitatif, jenis penelitian ini deskriptif kuantitatif, dan sifat penelitian ini adalah deskriptif eksplanatory. Metode analisis data adalah analisis regresi linear berganda. Teknik penentuan sampel menggunakan metode sampling jenuh. Sampel penelitian adalah 83 karyawan. Adanya pengaruh signifikan dan positif kompetensi, disiplin kerja, dan kepuasan kerja berpengaruh positif dan signifikan terhadap kinerja karyawan pada PT Nasatech Sukses Abadi Medan.
\end{abstract}

Kata Kunci : Kompetensi, Disiplin Kerja, Kepuasan Kerja, Kinerja Karyawan 


\section{PENDAHULUAN}

Sebagai salah satu bahan mentah dari bagian industri, kelapa sawit harus melewati berbagai proses yang membutuhkan mesin pabrik kelapa sawit (PKS). Proses tersebut bertujuan mengubah kelapa sawit menjadi minyak untuk berbagai kebutuhan seperti industri, rumah tangga dan lainnya. Pengolahan kelapa sawit menjadi bahan siap pakai membutuhkan serangkaian peralatan atau mesin untuk memudahkan pekerjaan tersebut. Penggunaan yang terus menerus memungkinkan terjadinya kerusakan pada mesin tersebut. Maka jasa servis mesin PKS terpercaya siap membantu. Namun terkadang spare part mesin pabrik kelapa sawit langka dan sulit didapatkan, hal itu dikarenakan mesin kelapa sawit merupakan produksi luar negeri. Jika ingin membeli sparepart aslinya akan membutuhkan waktu sangat lama yang akan mengganggu operasional pabrik. Perusahaan ini fokus di bidang pembuatan spare part mesin PKS, dan menjual spare part pabrik kelapa sawit harga bersaing.

Karyawan memiliki peranan besar dalam memenuhi kelancaran di bidang organisasi. Organisasi perlu sumber daya manusia guna mengembangkan usahanya. Kinerja seorang karyawan dapat diukur dari hasil kegiatan dalam kurun waktu tertentu terhadap apa yang dapat dikerjakan sesuai dengan tugas dan fungsinya (Kumarawati, et al., 2017). Faktor-faktor yang mempengaruhi kinerja karyawan salah satu nya adalah disiplin kerja.

PT Nasatech Sukses Abadi Medan merupakan sebuah perusahaan yang bergerak dibidang Produksi Sparepart KCP (Kelapa Sawit). Berdasarkan wawancara dan pengamatan yang dilakukan sebelumnya bahwa dalam perusahaan karyawan mengalami penurunan dalam kinerja. Penurunan kinerja dilihat dari penurunan kualitas kerja karyawan yang sering salah dalam penyelesaian tugas dan penyelesaian pekerjaan yang selalu tidak tepat waktu baik untuk karyawan lama ataupun baru serta tidak tercapainya target perusahaan.

Divisi yang paling banyak memiliki karyawan yang latarbelakang pendidikannya tidak sesuai adalah divisi accounting. Pada bagian accounting diterima lima karyawan yang latarbelakang pendidikannya adalah Sarjana Manajemen konsentrasi Pemasaran. Hal tersebut sangat berbeda dengan tugas accounting sehari - hari yang membutuhkan ketelitian dalam pembukuan. Permasalahan yang timbul adalah seperti karyawan sulit untuk mencapai target kerja, sulit beradaptasi dengan rekan kerja, mendapatkan penilaian kinerja yang rendah baik dari pimpinan maupun dari divisi HRD, dan tidak dapat melewati tes yang diberikan pihak HRD setiap bulannya.

Karyawan yang mengundurkan diri juga menjadi permasalahan pada faktor kepuasan kerja karyawan yang berdampak pada kinerja. Beberapa alasan karyawan mengundurkan diri adalah mengenai penerimaan kompensasi berupa gaji dan insentif yang masih tergolong kecil, tidak teratur dan tidak sesuai dengan beban kerja yang diterima karyawan kenaikan yang kecil dan lama, serta promosi jabatan yang tidak ada dan fasilitas yang kurang lengkap

Kinerja merupakan hasil kerja yang dapat dicapai seseorang atau sekelompok orang dalam suatu organisasi, sesuai dengan wewenang dan tanggungjawab masing-masing, dalam rangka upaya mencapai tujuan organisasi bersangkutan secara legal, tidak melanggar hukum dan sesuai 
dengan moral maupun etika (Saputra et al., 2016).

Kompetensi merupakan salah satu faktor kunci penentu bagi seseorang dalam menghasilkan kinerja yang sangat baik. dalam situasi kolektif, kompetensi merupakan faktor kunci penentu keberhasilan organisasi. Kompetensi juga merupakan karakteristik individu yang mendasari kinerja atau perilaku di dalam organisasi. Kinerja seseorang dipengaruhi oleh pengetahuan, kemampuan, sikap, gaya kerja, kepentingan, kepercayaan dan gaya kepemimpinan. Beberapa penelitian terdahulu telah mengkaji pentingnya kompetensi dalam menentukan kinerja karyawan dan menunjukkan hasil berpangaruh signifikan di antaranya penelitian Kusumo (2017), Manik \& Syafrina (2018)

Faktor lainnya selain kompetensi yang mempengaruhi kinerja adalah disiplin kerja. Disiplin kerja secara umum dapat didefinisikan sebagai cara suatu organisasi mewujudkan kinerja yang efektif dan efisien, serta lebih jauh mendukung terwujudnya visi dan misi organisasi (Saputra et al., 2016). Oleh karena itu, semakin tingg

Disiplin kerja seseorang, akan semakin tinggi juga kinerja orang tersebut. Kinerja karyawan akan dapat terwujud bila karyawan mempunyai komitmen dengan organisasi dan ditunjang dengan disiplin kerja yang tinggi (Purwati \& Kurniawan 2018).

Berdasarkan teori diatas bahwa disiplin kerja mempunyai pengaruh terhadap kinerja karyawan dalam mewujudkan kinerja yang efektif dan efisien di dalam perusahaan. Hal ini berarti bahwa semakin tinggi disiplin kerja seseorang, akan semakin tinggi juga kinerja orang tersebut. Penelitian oleh Saputra et al., (2016), menunjukkan bahwa disiplin kerja memberikan pengaruh signifikan terhadap peningkatan kinerja karyawan.

Selanjutnya kepuasan kerja merupakan variabel yang sangat memengaruhi kinerja individu dan organisasi. Kepuasan kerja bagi karyawan cenderung meningkatkan produktivitas, rasa bangga dan komitmen tinggi pada pekerjaanya. Ketika karyawan menilai suatu pekerjaan menyenangkan untuk dikerjakan, mereka mengatakan bahwa pekerjaan itu memberikan kepuasan kerja. Keadaan ini dapat dilihat dari hasil pekerjaannya, kepuasan kerja akan dapat meningkatkan kinerja mereka. Penelitian oleh Indrawati (2019), Arda (2017) menunjukkan kepuasan kerja berpengaruh signifikan terhadap kinerja karyawan.

\section{METODE PENELITIAN}

Dalam penelitian ini, peneliti menggunakan jenis penelitian deskriptif kuantitatif. Sifat penelitian yang digunakan adalah deskriptif explanatory. Populasi dalam penelitian ini berjumlah 83 karyawan. Sampel dalam penelitian ini berjumlah 83 karyawan. Teknik penentuan sampel adalah metode sampling jenuh. Teknik pengumpulan data mengunakan kuesioner, wawancara dan studi dokumentasi. Sumber data yang digunakan adalah data primer dan sekunder. Metode analisis data yang digunakan adalah analisi regresi linear berganda.

\section{HASIL DAN PEMBAHASAN Uji Validitas}

Hasil pengujian instrumen dari variabel stress kerja, kompetensi, disiplin kerja dan kinerja karyawan memiliki nilai $r_{h i t u n g}$ yang lebih besar dari $r_{\text {tabel }}$ dan nilai sig. dibawah 0,05 . 
Dengan demikian dapat disimpulkan bahwa seluruh instrumen pertanyaan dari variabel stress kerja, kompetensi, disiplin kerja dan kinerja karyawan yang digunakan adalah valid dan dapat digunakan dalam penelitian.

\section{Uji Reliabilitas}

Uji reliabilitas sebenarnya adalah alat untuk mengukur suatu kuesioner yang merupakan indikator dari variabel atau konstruk. Cronbach's alpha $<0.6=$ reliabilitas buruk.

1. Cronbach's alpha 0,6-0,79= reliabilitas diterima.

2. Cronbach's alpha 0,8 = reliabilitas baik.

Nilai Cronbach's Alpha dari seluruh variabel yang diujikan niainya sudah diatas 0,60, maka dapat disimpulkan bahwa seluruh variabel yaitu kompetensi, disiplin kerja, kepuasan kerja dan kinerja karyawan dalam penelitian ini lolos dalam uji reliabilitas dan dinyatakan reliabel.

\section{Uji Regresi Linear Berganda}

Pengujian hipotesis yang digunakan dalam penelitian adalah dengan menggunakan analisis regresi linier berganda. Rumus persamaan regresi linier berganda adalah sebagai berikut :

$$
\mathrm{Y}=\mathrm{a}+\mathrm{b}_{1} \mathrm{X}_{1}+\mathrm{b}_{2} \mathrm{X}_{2}+\mathrm{e}
$$

Model regresi yang digunakan adalah sebagai berikut

Tabel 1. Hasil Analisis Regresi Linear Berganda

\begin{tabular}{|c|c|c|c|c|}
\hline \multirow{2}{*}{\multicolumn{2}{|c|}{ Model }} & \multicolumn{2}{|c|}{$\begin{array}{c}\text { Unstandardized } \\
\text { Coefficients }\end{array}$} & \multirow{2}{*}{$\begin{array}{c}\begin{array}{c}\text { Standardized } \\
\text { Coefficients }\end{array} \\
\text { Beta }\end{array}$} \\
\hline & & $\bar{B}$ & Std. Error & \\
\hline \multirow{4}{*}{1} & (Constant) & ,481 & 5,511 & \\
\hline & KOMPETENSI & ,495 &, 197 & ,240 \\
\hline & DISIPLIN_KERJA & ,228 &, 110 & ,202 \\
\hline & KEPUASAN_KERJA & ,445 & ,115 & ,378 \\
\hline
\end{tabular}

Sumber: Data primer yang diolah, 2019
Kinerja Karyawan $=0,481+$ 0,495 Kompetensi+ 0,228 Disiplin Kerja + 0,445 Kepuasan Kerja. Penjelasan regresi linier berganda diatas adalah :

1. Konstanta sebesar 0,481 menyatakan bahwa jika variabel bebas kompetensi, disiplin kerja dan kepuasan kerja tidak ada atau konstan maka variabel terikat kinerja karyawan pada sebesar 0,481 satuan.

2. Koefisien regresi variabel bebas kompetensi sebesar 0,495 dan bernilai positif, hal ini menyatakan bahwa setiap kenaikan variabel bebas kompetensi 1 satuan akan meningkatkan variabel terikat kinerja karyawan sebesar 0,495 satuan dengan anggapan variabel lainnya tetap.

3. Koefisien regresi variabel bebas disiplin kerja sebesar 0,228 dan bernilai positif, hal ini menyatakan bahwa setiap kenaikan variabel bebas disiplin kerja 1 satuan akan menyebabkan kenaikan variabel terikat kinerja karyawan pada sebesar 0,228 satuan dengan anggapan variabel lainnya tetap.

4. Koefisien regresi variabel bebas kepuasan kerja sebesar 0,445 dan bernilai positif, hal ini menyatakan bahwa setiap kenaikan variabel bebas kepuasan kerja 1 satuan akan menyebabkan kenaikan variabel terikat kinerja karyawan pada sebesar 0,445 satuan dengan anggapan variabel lainnya tetap.

\section{Koefisien Determinasi Hipotesis}

Adjusted $R$ Square dinotasikan dengan $R^{2}$ merupakan nilai koefisien determinasi terkoreksi yang menyesuaikan $R^{2}$ dengan cara membagi tiap sum of square dengan derajat bebasnya masing-masing. 
Tabel 2. Uji Koefisien Determinasi

\begin{tabular}{lllll}
\hline \multicolumn{5}{c}{ Model Summary $^{\mathbf{b}}$} \\
\hline Model & $\mathrm{R}$ & $\begin{array}{l}\mathrm{R} \\
\text { Square }\end{array}$ & $\begin{array}{l}\text { Adjusted } \\
\text { R Square }\end{array}$ & $\begin{array}{l}\text { Std. Error of } \\
\text { the Estimate }\end{array}$ \\
\hline 1 &, $539^{\mathrm{a}}$ &, 291 &, 264 & 9,20370 \\
\hline Sumber: Data primer yang diolah, 2019
\end{tabular}

Tabel 2 menunjukkan bahwa hasil uji koefisien determinasi diperoleh nilai Adjusted $R$ Square sebesar 0,264 hal ini berarti $26,4 \%$ dari variasi variabel terikat yaitu kinerja karyawan yang dapat dijelaskan oleh variasi variabel bebas kompetensi, disiplin kerja dan kepuasan kerja sedangkan sisanya sebesar $73,6 \%(100 \%-26,4 \%)$ dijelaskan oleh variabel lain yang tidak diteliti pada penelitian ini, seperti pengembangan karir, promosi jabatan, kompensasi, motivasi kerja dan sebagainya.

\section{Pengujian Hipotesis Secara Simultan (Uji F)}

Pengujian statistik $F$ pada dasarnya menunjukkan apakah semua variabel bebas yang dimasukkan dalam model mempunyai pengaruh secara simultan terhadap variabel dependen.

Tabel 3 Uji Simultan (Uji F)

\begin{tabular}{|c|c|c|c|}
\hline \multicolumn{2}{|c|}{ Model } & $\mathrm{F}$ & Sig. \\
\hline \multirow{3}{*}{1} & Regression & 10,791 &, $000^{\mathrm{b}}$ \\
\hline & Residual & & \\
\hline & Total & & \\
\hline
\end{tabular}

Tabel 3 menunjukkan bahwa hasil pengujian diperoleh nilai $\mathrm{F}$ hitung $(10,791$ $>\mathrm{F}$ tabel $(2,72)$ dan probabilitas signifikansi $0,000<0,05$, berarti bahwa kompetensi, disiplin kerja dan kepuasan kerja positif dan signifikan secara simultan berpengaruh terhadap kinerja karyawan pada PT Nasatech Sukses Abadi Medan.
Pengujian Hipotesis Secara Parsial (Uji t)

Tabel 4 Uji Parsial (Uji t)

\begin{tabular}{lll}
\hline \multicolumn{1}{c}{ Model } & $\mathrm{t}$ & Sig. \\
\hline (Constant) &, 086 &, 932 \\
\hline KOMPETENSI & 2,511 &, 014 \\
\hline DISIPLIN_KERJA & 2,079 &, 041 \\
\hline KEPUASAN_KERJA & 3,864 &, 000 \\
\hline
\end{tabular}

Sumber: Data primer yang diolah, 2019

1. Hasil perhitungan pengujian hipotesis secara parsial diperoleh nilai $t_{\text {hitung }}>\mathrm{t}_{\text {tabel }}$ atau 2,511 $>1,990$ dan signifikan yang diperoleh 0,014 $<0,05$, berarti bahwa kompetensi positif dan signifikan secara parsial berpengaruh terhadap kinerja karyawan pada PT Nasatech Sukses Abadi Medan.

2. Hasil perhitungan pengujian hipotesis secara parsial diperoleh nilai $t_{\text {hitung }}>t_{\text {tabel }}$ atau 2,079 $>1,990$ dan signifikan yang diperoleh 0,041 $<0,05$, berarti bahwa disiplin kerja positif dan signifikan secara parsial berpengaruh terhadap kinerja karyawan pada PT Nasatech Sukses Abadi Medan.

3. Hasil perhitungan pengujian hipotesis secara parsial diperoleh nilai thitung $>\mathrm{t}_{\text {tabel }}$ atau 3,864 >1,990 dan signifikan yang diperoleh 0,000 $<0,05$, berarti bahwa kepuasan kerja positif dan signifikan secara parsial berpengaruh terhadap kinerja karyawan pada PT Nasatech Sukses Abadi Medan.

\section{Pengaruh Kompetensi terhadap Kinerja Karyawan}

Hasil perhitungan pengujian hipotesis pertama ditemukan bukti bahwa nilai $t_{\text {hitung }}>\mathrm{t}_{\text {tabel }}$ atau 2,511 > 1,990 dan signifikan yang diperoleh $0,014<0,05$, berarti bahwa kompetensi positif dan signifikan berpengaruh secara parsial terhadap kinerja 
karyawan pada PT Nasatech Sukses Abadi Medan. Hal ini berarti mendukung hipotesis pertama. Hasil pengujian secara statistik juga sejalan hasil penelitian yang dilakukan oleh Kusuma (2017), Manik \& Syafrina (2018) dimana kompetensi merupakan faktor kunci penentu bagi seseorang dalam menghasilkan kinerja yang sangat baik. Dalam situasi kolektif, kompetensi merupakan faktor kunci penentu keberhasilan organisasi.

\section{Pengaruh Disiplin Kerja terhadap Kinerja Karyawan}

Hasil perhitungan pengujian hipotesis kedua diperoleh nilai $t_{\text {hitung }}>$ $t_{\text {tabel }}$ atau 2,079 > 1,990 dan signifikan yang diperoleh $0,041<0,05$, berarti bahwa disiplin kerja positif dan signifikan secara parsial berpengaruh terhadap kinerja karyawan pada PT Nasatech Sukses Abadi Medan. Hal ini mendukung hipotesis kedua Sejalan dengan penelitian yang dilakukan oleh Saputra et al., (2016), yang juga menunjukkan bahwa disiplin kerja memperngaruhi kinerja karyawan secara positif. Kinerja karyawan akan dapat terwujud bila karyawan mempunyai komitmen dengan organisasi dan ditunjang dengan disiplin kerja yang tinggi (Budiman et al., 2016).

\section{Pengaruh Kepuasan Kerja terhadap Kinerja Karyawan}

Hasil perhitungan pengujian hipotesis ketiga diperoleh nilai $t_{\text {hitung }}>$ $t_{\text {tabel }}$ atau 3,864 >1,990 dan signifikan yang diperoleh $0,000<0,05$, berarti bahwa kepuasan kerja positif dan signifikan secara parsial berpengaruh terhadap kinerja karyawan pada PT Nasatech Sukses Abadi Medan. Hal ini mendukung hipotesis ketiga. Sejalan dengan penelitian oleh Indrawati (2019), Arda (2017) dimana kepuasan kerja berpengaruh signifikan terhadap kinerja karyawan. Kepuasan kerja merupakan variabel tergantung utama karena dua alasan yaitu menunjukkan hubungan dengan faktor kinerja dan merupakan prefeerensi nilai yang dipegang banyak peneliti perilaku organisasi.

\section{PENUTUP \\ Kesimpulan}

Berdasarkan hasil analisis data yang dilakukan pada PT Nasatech Sukses Abadi Medan maka dapat disimpulkan bahwa disiplin kerja, dan kepuasan kerja berpengaruh positif dan signifikan terhadap kinerja karyawan. Hasil perhitungan pengujian hipotesis menunjukkan bahwa kompetensi, disiplin kerja dan kepuasan kerja positif dan signifikan secara simultan berpengaruh terhadap kinerja karyawan

\section{Saran}

Bagi perusahaan, disarankan agar dapat memberikan peluang berupa kenaikan gaji, memfasilitasi karyawan dalam mempererat hubungan kerja seperti mengadakan outbond sekali dalam setahun, dan mengembangkan ketrampilan atau kemampuan karyawan seperti pelaksanaan studi banding ke perusahaan dengan bidang yang sama. Bagi peneliti selanjutnya dimasa yang akan datang disarankan menambahkan variabel kompensasi, pelatihan, disiplin, dan variabel lain yang mempengaruhi kinerja. Penelitian selanjutnya dapat mengadakan penelitian di bidang jasa perbankan atau perusahaan manufaktur.

\section{DAFTAR PUSTAKA}

Arda, M. (2017). Pengaruh Kepuasan Kerja dan Disiplin Kerja Terhadap Kinerja Karyawan Pada Bank Rakyat Indonesia Cabang Putri HIjau 
Medan. Jurnal Ilmiah Manajemen dan Bisnis, 18(1), 45-60.

Budiman, N., P., Saerang, I., S., \& Sendow, G., M. (2016). Pengaruh Kompetensi, Motivasi, dan Disiplin Kerja Terhadap Kinerja Karyawan (Studi Pada PT. Hasjrat Abadi Tendean Manado). Jurnal EMBA: Jurnal Riset Ekonomi, Manajemen, Bisnis dan Akuntansi, 4(3).

Indrawati, A., D. (2019). Pengaruh kepuasan kerja terhadap kinerja karyawan dan kepuasan pelanggan pada rumah sakit swasta di kota denpasar. Matrik: Jurnal Manajemen, Strategi Bisnis dan Kewirausahaan.

Kumarawati, N., M., R., Suparta, G., \& Yasa, P., N., S. (2017). Pengaruh Motivasi Terhadap Disiplin dan Kinerja Pegawai Pada Sekretariat Daerah Kota Denpasar. Jurnal Ekonomi \& Bisnis JAGADITHA, 4(2), 6375.

Kusuma, A., H., P. (2017). Pengaruh kompetensi, budaya organisasi dan motivasi terhadap kinerja dosen perguruan tinggi swasta di kota makassar. Economics Bosowa, 3(8), 88-100.

Manik, S., \& Syafrina, N. (2018). Pengaruh Kompetensi Terhadap Kinerja Dosen Sekolah Tinggi Ilmu Ekonomi Riau. Jurnal Ilmiah Ekonomi Dan Bisnis (JIEB), 15(1), 16.

Purwati, A. A., \& Kurniawan, J. (2018). Analisis Pengaruh Gaji, Kedisiplinan Dan Pembagian Kerja Terhadap Kinerja Guru Dan Karyawan Di Sekolah Esa Sejahtera Pekanbaru. Jurnal Cano Ekonomos, 7(1), 16-24.
Saputra, I., P., A., Bagia, I., W., S., M., \& Suwendra, I. W. (2016). Pengaruh Kompetensi Dan Disiplin Kerja Terhadap Kinerja Karyawan. Jurnal Manajemen Indonesia, 4(1) 